\title{
LAS TRADICIONES DE RICARDO PALMA, UN CIERTO SABER HISTÓRICO
}

\author{
FRANCISCO JOSÉ LÓPEZ ALFONSO
}

$\overline{\text { Francisco José López Alfonso }}$

Profesor Titular de la Universidad de Valencia, es autor de los libros, César Vallejo, las trazas del narrador y «Hablo, señores de la libertad para todos» (López Albújar y el indigenismo en el Perú) y editor de la antología Indigenismo y propuestas culturales. Actualmente tiene en prensa una biografía y antología de José Carlos Mariátegui.

Ha publicado artículos sobre la narrativa del período de Independencia -la novela Jicoténcal y las novelas de Fernández de Lizardi-, literatura brasileña -Machado de Assís, Guimaraes Rosa, Rubem Fonseca, Dalton Trevisan- y literatura de vanguardia -el mencionado Vallejo, Pablo Palacio, Roberto Arlt-, novela regionalista y diversos autores.

$\mathrm{Al}$ igual que El Quijote de Pierre Menard, Las tradiciones peruanas de Ricardo Palma incorporan inevitablemente el juicio acerado que de ellas hiciera Manuel González Prada. Como presidente del Círculo Literario y vocero de la nueva generación, González Prada negaba a Palma los valores de guía y maestro y arremetía contra las Tradiciones:

¿Quién debe guiarnos?

Ningún escritor nacional ni español.

Aquí nadie tiene que arrogarse el título de maestro, porque todos somos discípulos o aficionados. (...)

Cultivamos una literatura de transición, vacilaciones, tanteos y luces crepusculares. De la poesía van desapareciendo las descoloridas imitaciones de Bécquer; pero en la prosa reina siempre la mala tradición, ese monstruo engendrado, por las falsificaciones agridulcetes de la historia la caricatura microscópica de la novela ${ }^{1}$.

Estas palabras del «Discurso en el Teatro Olimpo», pronunciado en octubre de 1888, marcaron el distanciamiento entre ambos escritores y, sobre todo, marcaron muchas de las lecturas que hasta el día de hoy se han hecho de la obra de Palma. Ya Rufino Blanco Fombona en el prólogo que escribió para la segunda edición de Pájinas libres (Madrid, 1915) se hacía eco de la insidia y concretaba «las falsificaciones agridulcetes de la historia» en un elogio del virreinato, en un canto del esclavo a sus dominadores. Palma resultaba así -cito- «un españolizante, un retardatario, un espíritu servil, un hombre de la colonia»².

Todavía más fiel al ataque de González Prada resultaba Federico More, quien en un ensayo de 1924 demostraba lo bien que se había aprendido la lección: «Ricardo Palma -escribía-, representativo, expresador y centinela del Colonialismo, es un historizante anecdótico, divertido narrador de chascarrillos fichados y anaquelados. Escribe con vistas a la Academia de la lengua y, para contar los devaneos y discreteos de las marquesitas de pelo ensortijado y labios prominentes, quiere usar el castellano del siglo de oro» ${ }^{3}$.

El anatema continúa repitiéndose bastantes años después en los textos de José Miguel Oviedo. En el prólogo que acompaña a su antología de las Tradiciones para Biblioteca Ayacucho el calificativo "agridulcete» prolonga su efecto corrosivo, de manera que -cito- «Palma no adora irrestrictamente la colonia (...). Pero su crítica nunca es tajante, (...). El espíritu de Palma no es tanto colonialista, como ambiguo y tolerante: aunque encuentre en el pasado motivos de repudio, eso no lo aparta de él (...). Puede tener defectos, pero el pasado es su refugio, su paraíso psicológico cuando la época actual lo hiere con su prosaísmo y practicidad. Su evasión al pasado está llena de concesiones». Su imagen de la colonia es "complaciente y cortesana», «ajena a los niveles problemáticos de la realidad» ${ }^{4}$.

Esta ambigua y tolerante interpretación se perfila en un estudio posterior, que hace de Palma el gestor de «una añorante alianza con el pasado» para afirmar una imagen nacional del Perú y para encontrar en ese pasado el linaje literario que lo elevará desde sus orígenes de medio pelo, esto es, de clase media baja. «Se convirtió literariamente -sentencia Oviedo- en un reaccionario para que la Lima semicolonial del XIX se inclinase ante él» ${ }^{5}$.

En una línea muy próxima se expresa Antonio Cornejo Polar. De hecho, valora
1

Manuel González Prada, «Discurso en el Teatro Olimpo», en Manuel González Prada, Páginas libres. Horas de lucha, Barcelona, Biblioteca Ayacucho, 1985, pp. 25-33 (p. 27).

Citado por Walter J. Peñaloza, "Significado de Palma en la cultura peruana», en Ángel Flores, Orígenes del cuento hispanoamericano. Ricardo Palma y sus Tradiciones, México, Premia Editora, 1979, pp. 11-28 (p. 18).

3

Citado por José Carlos Mariátegui, Siete ensayos de interpretación de la realidad pervana, Barcelona, Editorial Crítica, 1976, p. 204.

José Miguel Oviedo, «Palma en tre ayer y hoy», en Ricardo Palma, Cien Tradiciones Peruanas, Caracas, Biblioteca Ayacucho, 1977, pp. ix-xlv, pp. xxxvi y xl.

5

José Miguel Oviedo, «Palma y su 'nueva' manera de narrar», en Flores, op. cit., pp. 31-44 (pp. 34 y 43$)$. 


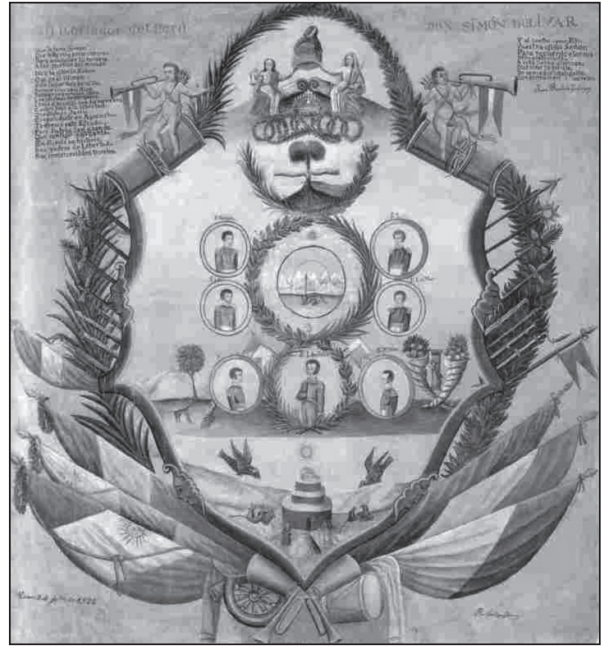

Anónimo, Escudo alegórico en honor a Bolivar. 1825 Instituto Nacional de Cultura, Cuzco, Museo Histórico Regional.

6

Antonio Cornejo Polar, La formación de la tradición literaria en el Perú, Lima, CEP, 1989, pp. 58-59.

7 Ibid., p. 60

8

José de la Riva Agüero, Carácter de la literatura del Perú independiente, Lima, E. Rosay Editor, 1905 , pp. 150 y 151

9

Ibid., p. 142

10

Cornejo Polar, op. cit., p. 66.

11

Víctor Raúl Haya de la Torre "Nuestro frente intelectual», Amauta, 4 (1926), pp. 3-4 y 7-8 (p. 4).

12

Mariátegui, op. cit., p. 200

Las tradiciones de Ricardo Palma, un cierto saber histórico

FRANCISCO JOSÉ LÓPEZ ALFONSO un libro de Oviedo -Genio $y$ figura de Ricardo Palma, Buenos Aires, Editorial Universitaria de Buenos Aires, 1965- como el más útil de los escritos sobre Palma y las Tradiciones. Así, para Cornejo las Tradiciones también elaboran una imagen edulcorada de la colonia, en la que nada, dice, «era muy trágico, ni muy injusto, ni siquiera las hogueras de la Inquisición» ${ }^{6}$. En este proyecto palmista, la supresión de las contradicciones sociales resulta fundamental. El humor, acompañado por el desarrollo de la anécdota, es, según Cornejo, el instrumento adecuado para ello.

El hecho de que Palma escriba sus narraciones a partir de fuentes coloniales sería la prueba de su vínculo afirmativo con estas raíces. De este modo, las Tradiciones pasan a ser nada menos que «la continuación republicana del discurso colonial» ${ }^{7}$. La colonia, como locus amoenus, es, según Cornejo, el origen de la tradición nacional en la literatura del Perú, de su imagen simbólica. Pero esta imagen nacional, a cuya formación coadyuvaron los paralelos trabajos historiográficos y filológicos de Palma, no es solo falsa, sino altamente excluyente, restrictiva.

Esta interpretación coincide con la de José de la Riva Agüero -de la que es claramente deudora, como lo es también la de Oviedo-, pero valora de forma muy diferente sus conclusiones. En su Carácter de la literatura del Perú independiente (1905), Riva había desplazado el «agridulcete» de González Prada de la tradición a la misma historia:

...los blancos criollos -escribe- no hacen sino divertirse. Padece el indio en la Sierra, padece el negro en el campo, y estos son los lados obscuros de la Colonia; en cambio la aristocracia, la clase media y el pueblo de las ciudades viven sin dolores ni preocupaciones, con la imprevisión y la inocente fatuidad de los niños ${ }^{8}$.

Palma, entonces, sería simplemente un escritor con vocación realista y citadina, que si apenas presta atención a la historia incaica es porque «tiene mucho de exótica y extraña (...) no la sentimos -escribe Riva, atribuyendo sus prejuicios a Palma- con el afecto íntimo con que apreciamos la de la Colonia»`. En defini- tiva, si para Cornejo «el proyecto representado por las Tradiciones no es hispanista» ${ }^{10}$, no deja de estar muy condicionado por la lectura que de ellas hizo Riva Agüero.

Por fortuna, existe otra corriente crítica que, al desentenderse del enfrentamiento entre Palma y Prada, no ha incurrido en los errores propiciados por una historiografía de banderías, tan simplificadora como deformante y que establece la existencia de dos tradiciones literarias en el Perú: la primera, criolla y blanca, colonialista y limeña, conservadora, y la segunda, mestiza e indígena, indigenista y provinciana, progresista.

Curiosamente, fueron los belicosos miembros de la generación de la Reforma Universitaria, tan propensos a estos enfrentamientos, los que comprendieron que, a pesar de diferencias, Palma y Prada se movían animados por una general idea de progreso.

Haya de la Torre, en un escrito publicado en el número 4 de la revista Amauta, exhortaba a la revisión de la figura y la obra de Palma para colocarla «al lado de Prada», destacando el uso que el autor de las Tradiciones hacía de la ironía como «un arma formidable contra el pasado ridículo, de coloniaje, de esclavitud, de sumisión dichosa» ${ }^{11}$.

Y Mariátegui, en el judicial «Proceso de la literatura» de sus Siete ensayos, denunciaba cualquier intento de considerar a Palma un representante del colonialismo. «Las Tradiciones -afirma- no pueden ser identificadas con una literatura de reverente y apologética exaltación de la Colonia y sus gustos (...)». Eso es lo que ofrecían Felipe Pardo y José Antonio Lavalle en sus nostálgicas evocaciones, mientras que Palma la reconstruye «con un realismo burlón y una fantasía irreverente y satírica». Este espíritu -señala Mariáteguies «demasiado evidente en toda la obra» ${ }^{12}$; y aun así, esta evidencia no ha bastado para que algunos, muchos, lo hayan hecho caminar hacia atrás, como Caco a sus bueyes, como si quisiera volver al pasado, cuando, en realidad, quería salir de él.

Ciertamente, el interés de Palma por la historia no surge del afán de escudriñar el pasado como tal. Su propósito no se limita a recuperar los acontecimientos del polvo al que los condenaría el olvido y, mucho menos, a ver en ellos motivos dignos de recuerdo y celebración. Sin embargo, la declaración que abre «Un virrey y un arzobispo», publicada por primera vez en la Revista de Sud América, en 1861, cuando todavía se estaba gestando la tradición, parecería afirmar lo contrario. 
La época del coloniaje, fecunda en acontecimientos que de una manera providencial fueron preparando el día de la Independencia del Nuevo Mundo, es un venero poco explotado aún por las inteligencias americanas.

Por eso, y perdónese nuestra presuntuosa audacia, cada vez que la fiebre de escribir se apodera de nosotros, demonio tentador al que mal puede resistir la juventud, evocamos en la soledad de nuestras noches al genio misterioso que guarda la historia de ayer de un pueblo que no vive de recuerdos ni de esperanzas, sino de actualidad.

Lo repetimos: en América la tradición apenas tiene vida. La América conserva todavía la novedad de un hallazgo y el valor de un fabuloso tesoro apenas principiado a explotar.

Sea por indolencia de los gobiernos en la conservación de los archivos, o por descuido de nuestros antepasados en no consignar los hechos, es innegable que hoy sería muy difícil escribir una historia cabal de la época de los virreyes. Los tiempos primitivos del imperio de los Incas, tras los que está la huella sangrienta de la conquista, han llegado hasta nosotros con fabulosos e inverosímiles colores. Parece que igual suerte espera a los tres siglos de dominación española.

Entre tanto, toca a la juventud hacer algo para evitar que la tradición se pierda completamente. Por eso, en ella se fija de preferencia nuestra atención, y para atraer la del pueblo creemos útil adornar con las galas del romance toda narración histórica ${ }^{13}$.

La tradición no es el pasado, sino el hilo que nos une a él. Y las nuevas repúblicas, tras la Independencia, quisieron cortarlo definitivamente. La emancipación representaba romper con la metrópoli, pero, sobre todo, romper con el modelo social que ésta encarnaba, el antiguo régimen. Era el tránsito de una sociedad teocrática a una sociedad civil; esto es, de una sociedad fundada en principios irracionales a una sociedad regida por la razón. De hecho, la Emancipación, como su principal modelo ideológico, la Revolución francesa, era el cumplimiento del proyecto modernizador que conocemos como Ilustración.

Sin embargo, las nuevas repúblicas no confirmaron los ideales que habían animado a los libertadores. La libertad había sido suplantada por la anarquía y el despotismo y, en lugar del orden esperado, lo que todos percibieron fue el caos sin sentido, un caos cuya forma más cruda era la guerra. La vida se militarizó.

El fenómeno fue general y el Perú no constituyó la excepción. Durante los primeros cincuenta años de República, todos los gobiernos fueron autocráticos y anticonstitucionales. Pese a algún remanso de paz, la guerra civil siempre estaba en puertas. La inesperada riqueza del guano y del salitre supuso la entrada oficial del país en el mercado internacional. Y bajo el gobierno de José Balta, del que Palma fue secretario personal, el Perú experimentó una modernización notable: impulso de las obras públicas, extensión de los ferrocarriles, reconstrucción y mejora de los puertos. Aun así, continuaba siendo un país eminentemente agrícola, con un sistema productivo arcaico, basado en la propiedad latifundista, y una situación social que había tenido muy pocos cambios desde la colonia. Como Mariátegui describió certeramente: «El régimen económico-social de la colonia se adaptó externamente a las instituciones creadas por la revolución. Pero la saturó de su espíritu colonial» ${ }^{14}$.

Similar comprensión alcanzó Palma. Percibió que la sociedad peruana del siglo XIX vivía con un doble registro de valores y usos. Mientras que el pueblo, en el campo o en la ciudad, continuaba viviendo en un mundo de raíces sacras, los grupos dominantes exhibían las formas prestigiosas de los modernos valores burgueses, pero seguían reclamando y ejerciendo sus viejos privilegios estamentales. «Nada cambió en mi tierra-escribía Palmasino un tratamiento: al excelentísimo señor virrey se le sustituyó con el excelentísimo señor presidente» ${ }^{15}$. Era el mismo universo contradictorio que por las mismas fecha parodió de manera genial el brasileño Machado de Assís en Las memorias póstumas de Blas Cubas.

Al tiempo que lo invadía un agudo sentimiento de desencanto por las promesas no cumplidas, Palma pensaba que únicamente la historia podía arrojar luz sobre los problemas de la República: ¿por qué estamos así?, ¿por qué el progreso no se ha hecho efectivo?, ¿por qué, si el pasado ha perdido su autoridad, impide que llegue el futuro? Éstas son algunas de las preguntas que se encuentran en el origen de las Tradiciones y que resuenan en esa declaración que abre «Un virrey y un arzobispo».

Sin duda, a Palma le influenció el historicismo de su tiempo, como a tantos espíritus inquietos. Muchas eran las razones para el inmenso crecimiento de los estudios históricos a lo largo del siglo XIX: la desintegración de las antiguas instituciones religiosas y sociales, la transformación revolucionaria de

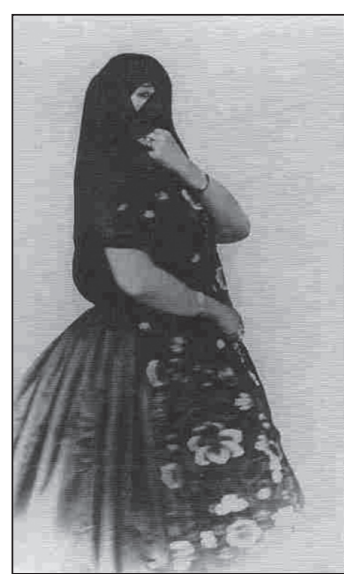

Anónimo. Mujer limeña. Fotografía. Pinacoteca de la Municipalidad de Lima.

13 Palma, «Un virrey y un arzo bispo», op. cit., pp. 103-114, p. 103.

14

Mariátegui, op. cit., p. 203

15

Carta al Marqués de Laurencia, agosto, 18 de 1909, citado por Oviedo, op. cit., en Flores, op. cit., p. 41.
Las tradiciones de Ricardo Palma, un cierto saber histórico

FRANCISCO JOSÉ LÓPEZ ALFONSO 


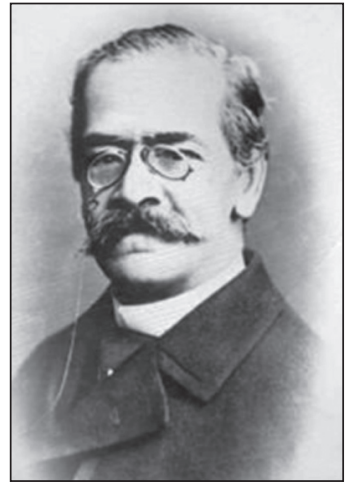

Ricardo Palma.

16

Hannah Arendt, Entre el pasado y el futuro. Ocho ejercicios sobre la reflexión política, Barcelona, Editorial Península, 1996, p. 73.

17

Ibid., p. 103.

18

Id. El subrayado es nuestro.

19

Rafael Gutiérrez Girardot, «La formación del intelectual hispanoamericano en el siglo $X \mid X »$, en El intelectual y la historia, Caracas, Fondo editorial La Nave Va, 2001, pp. 57-106 (p. 60).

20

Citado por Oviedo, op. cit., en Palma, op. cit., p. xv.

Las tradiciones de Ricardo Palma, un cierto saber histórico

FRANCISCO JOSÉ LÓPEZ ALFONSO algunas sociedades, el surgimiento de nuevos estados.... Todos estos cambios estimularon necesariamente la investigación histórica y algunos grandes pensadores se plantearon la posibilidad de descubrir las leyes que gobiernan el mundo social, como Newton y otros científicos habían encontrado las que rigen el mundo natural. Si tales leyes llegasen a ser descubiertas deberían ser válidas para explicar el pasado y también para controlar el futuro.

Palma no contempla tal precisión, pero su concepto de historia sí considera la idea de proceso; una idea que, según Hannah Arendt, «separa la época moderna del pasado con mayor profundidad que cualquier otra idea por sí sola. Para el pensar moderno, nada es significativo en sí y por sí mismo, ni siquiera la historia o la naturaleza» ${ }^{16}$. Por eso, al referirse a la colonia en «Un virrey y un arzobispo» afirma que fue «fecunda en acontecimientos que de una manera providencial fueron preparando el día de la Independencia del Nuevo Mundo» ${ }^{17}$.

Eso es lo que implica la idea de proceso, que lo concreto y lo general son concomitantes, que el acontecimiento particular y el significado universal se corresponden, que el presente no puede comprenderse sin el pasado y que, sin ambos, no existe posibilidad de futuro; precisamente lo que afirma Palma, justificando la necesidad de la tradición: «(...) evocamos en la soledad de nuestras noches al genio misterioso que guarda la historia de ayer de un pueblo que no vive de recuerdos ni de esperanzas, sino de actualidad» ${ }^{18}$.

Ante esta necesidad política, la cuestión de la literatura nacional -ese «fabuloso tesoro» apenas explotado que recuerda el desierto de «La advertencia» a La cautiva de Echeverría- queda reducido a su justo término o bien revela su auténtica dimensión: la literatura nacional como libertadora del pasado; del mismo modo que el temor a que se pierda la tradición colonial no expresa amor al pasado sino al presente.

En cualquier caso, el peligro de que se perdiese el testimonio del pasado era grande y, como dice el texto, en buena medida, se debía a «la indolencia de los gobiernos en la conservación de los archivos». Y es que para los ciudadanos de las recién nacidas repúblicas americanas, la colonia era un mal sueño. Cuanto quedase de ella debía eliminarse, pues la colonia, como España, era sinónimo de bárbaro, de atrasado, de opresor, de vulgar. Como ha señalado, Rafael Gutiérrez Girardot, el proyecto de racionalización de la nueva sociedad «se entendió de manera negativa, es decir, como una contraposición al pasado colonial español». Esta equívoca concepción tuvo como consecuencia la incapacidad de considerar ese pasado como realidad «de la que había que partir para superarla», en lugar de obviarla como si no hubiese existido nunca ${ }^{19}$.

Aunque poeta e historiador, figuras a las que Aristóteles sitúa dentro de la misma categoría, la tarea que Palma se impone no puede consistir en hacer algo que sea digno de recuerdo, porque no hay dignidad en ese pasado. Es un pasado enemigo y por eso es preciso conocerlo, para poder combatirlo.

Seguramente Palma no leyó a Hegel, pero con toda probabilidad leyó a Walter Scott en las ediciones españolas que Moreno y Jordán prepararon en 1830, y que fueron muy populares en el Perú. Y quizá en la obra de Scott, que guarda un gran paralelismo con la filosofía hegeliana de la historia, advirtiese que lo nuevo se contrapone hostilmente a lo viejo y que la trasformación se vincula de manera necesaria a la destrucción del anterior modo de realidad.

Pero en las ex-colonias españolas, lo viejo, a menudo disfrazado de lo nuevo, invisible, había demostrado un vigor extraordinario. Las Tradiciones, entonces, asumían políticamente la labor que en el mundo europeo cumplió la historiografía de la Ilustración: demostrar la necesidad de subvertir la irracional sociedad feudal y absolutista; con la paradójica diferencia de que, supuestamente, la emancipación ya había consumado ese deber.

El esclarecimiento del pasado genera per se ideología y aún más cuando ese pasado es la colonia, cuya esencia reconoció Palma, como antes lo había hecho Sarmiento, en la Inquisición. No es ninguna casualidad, por tanto, que Palma iniciara su pionera trayectoria de historiador con la publicación de los Anales de la Inquisición de Lima, en 1863, denunciando el espíritu represor con el que España había tratado a sus colonias y se había tratado a sí misma para sofocar la capacidad de pensar y de actuar guiado por ese pensamiento. Y aún es menos casualidad que en 1910 incluyera estos Anales como parte de Apéndice a mis últimas tradiciones y lo justificara con estas palabras:

Este libro hizo brotar en mi cerebro el propósito de escribir Tradiciones. Por eso estimo, como complementario de mi afortunada labor, terminar esta publicación reproduciendo, a guisa de remate y contera, estos Anales, que, en puridad de verdad, son también Tradiciones ${ }^{20}$. 
El propósito de las Tradiciones es manifiesto y afín ideológicamente con el resto de las producciones de Palma. Cómo ignorar su Refutación a un compendio de bistoria del Perú, de 1886, en el que arremetía indignado contra el jesuita español Ricardo Cappa, autor de un manual de Historia del Perú. El padre Cappa, condenaba Palma,

...pretende enseñar a nuestros hijos que los Incas eran bárbaros opresores, dignos de ser condenados; que el coloniaje fue todo bienandanza; que la República es una vergüenza, los próceres de la Independencia, ambiciosos sin antecedentes y verdaderos monstruos; la Inquisición una delicia cuyo restablecimiento convendría; la libertad de imprenta una iniquidad; Bolivar, San Martín y Monteagudo tres peines entre los que distribuye los calificativos de obsceno, cínico, pérfido, aleve, inmoral, malvado, etc. Es imposible reconcentrar más veneno contra el Perú y sus hombres en menos páginas ${ }^{21}$.

Y, sin embargo, para Cornejo, Palma «revive el pasado y lo hace vigente como tradición todavía fuerte y fértil», "combate los juicios y prejuicios anticoloniales» ${ }^{22}$. Quizá ha visto en las Tradiciones la estatua ecuestre de algún conquistador, de algún virrey o de un monarca que, como aquélla de Pedro I que evocaba Joseph de Maestre, extiende su terrible brazo sobre su posteridad, sin que pueda saberse si esa mano de bronce protege o amenaza; pero yo no encuentro tal pasaje $\mathrm{e}^{23}$.

Con mayor sensibilidad literaria, Juan Valera escribía a Palma en sus Cartas americanas:

En esas historias que usted refiere como el vulgo y las viejas cuentan cuentos; donde hay, según usted afirma, algo de mentira, yo no conozco ni sospecho la mentira sino en las menudencias. Lo esencial, lo de más bulto, es verdad del todo en mi sentir. Tengo la firme persuasión de que no hay historia grave, severa y rica de documentos que venza a las Tradiciones de usted en dar idea clara de lo que fue el Perú hasta hace poco y en presentar su fiel retrato ${ }^{24}$.

La convicción de Valera es general; incluso es compartida por historiadores profesionales. Raúl Porras Barrenechea afirmaba que la imborrable «impresión de historia» que dejan las Tradiciones es permanente, porque en conjunto «parece más historia que la historia misma» 25 .

Palma alcanza ese efecto de autenticidad histórica porque logra, digamos, despertar a la vida tiempos remotos. Y lo consigue, recreando una intensa interacción entre los per- sonajes -reales o ficticios-y su entorno social e ideológico; de tal modo que fuera de ese contexto que los explica no tendrían sentido. Autenticidad histórica es, pues, para Palma la peculiaridad temporalmente condicionada.

Sin embargo, sin una relación vital con el presente no sería posible la configuración de ese pasado. Pero esa relación no consiste en aludir a acontecimientos o situaciones contemporáneas, sino en la utilización del pasado como historia previa y necesaria del presen$\mathrm{te}^{26}$. Puede que en las Tradiciones abunden las alusiones que establecen paralelismos entre la colonia y la República -«caídos y levantados, hartos y hambrientos, eso fue la colonia, y eso ha sido y es la república. La ley del yunque y del martillo imperando a cada cambio de tortilla», se lee, por ejemplo, en «Los caballeros de la capa» ${ }^{27}-$; pero no son más que avisos, insistencias que resultarían inútiles si no estuviesen insertas en una concepción de la historia que afirma que lo nuevo se contrapone hostilmente a lo viejo, que la opresión y la libertad se combaten sin piedad, que la historia es un proceso. Por ello, aunque se centrasen de manera lógica en el universo colonial, dado que constituía la realidad de la que partía y mejor representaba ese despotismo eviterno, las Tradiciones daban cuenta también de la República y hasta del Incario.

Hegel ha escrito: «Lo histórico es nuestro sólo... cuando podemos contemplar el presente como consecuencia de aquellos acontecimientos en cuya cadena los caracteres o los hechos representados son un eslabón esencial» ${ }^{28}$. La verdad de las Tradiciones, a la que se refería Valera, estriba en esa necesidad histórica. Frente a esa autenticidad no tiene importancia alguna el que personajes, hechos o detalles sueltos sean o no documentables. Es más, paradójicamente, esa verdad requiere del anacronismo. Hay que infundir lo nuevo en todas las circunstancias para que éstas sean intuibles; de manera tal que la imagen de la colonia está entreverada por los valores liberales que Palma defendía. Resumiendo, las Tradiciones pueden ser interpretadas en su conjunto como prehistoria de un presente orientado por fines completamente distintos; pues Palma fue, como quería de cualquier poeta, «hombre y hombre de su siglo».

La literatura de Palma, como anteriormente las novelas de Fernández de Lizardi o el Facundo de Sarmiento, está comprometida con el proyecto modernizador de las ex-colonias españolas; aspira a erigir la razón en principio organizador de la sociedad. Pero

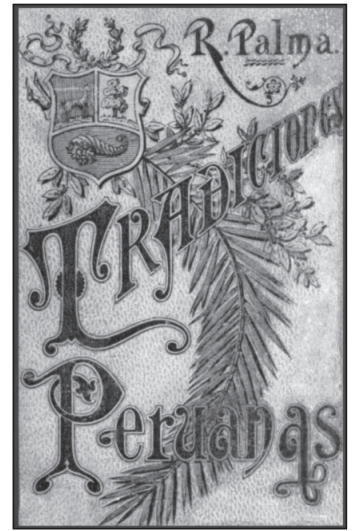

Tradiciones peruanas (primera serie). Portada.

21

Citado por Rosa Arciniega, «Volterianismo», en Flores, op. cit., pp. 81-85 (p. 85)

22

Cornejo Polar, op. cit., pp. 57 y 62.

23

Una interesante reflexión sobre la cuestión que se aborda en este trabajo, pero que no se agota en la obra de Palma puede leerse en Eva $M^{a}$ Valero Juan, Lima en la tradición literaria del Perú, Lleida, Edicions de la Universitat de Lleida, 2003.

24

Citado por Riva Agüero, op. cit., pp. 139-140.

25

Citado por Oviedo, op. cit., en Palma, op. cit., p. xxxiii

26

Véase al respecto Georg Lukács, La novela histórica, Barcelona, Grijalbo, 1976, principalmente pp. 51 y ss.

27 Palma, "Los caballeros de la capa», op. cit., pp. $29-40$, p. 29.

28

Citado por Lukács, op. cit., p. 54 .

Las tradiciones de Ricardo Palma, un cierto saber histórico

FRANCISCO JOSÉ LÓPEZ ALFONSO 


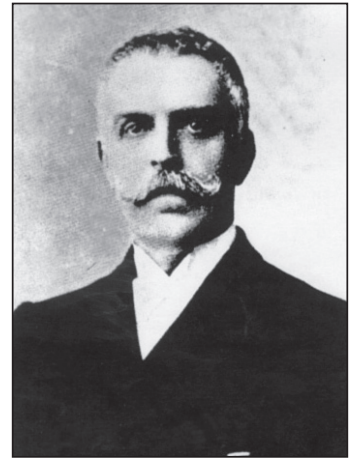

Manuel González Prada.

29

Sobre esta cuestión véase $\mathrm{Al}$ berto Escobar, «Tensión, lenguaje y estructura. Las Tradiciones peruanas», en Patio de letras, Caracas, Monte Ávila editores, 1972, pp. 77-165.

30

La acertada imagen es de Julio Ortega, Crítica de la identidad. La pregunta por el Perú en su literatura, México, Fondo de Cultura Económica, 1988, p. 36.

31

Antonio Cornejo Polar, op. cit., p. 59 .

32

Citado por Escobar, op. cit., p. 133

33

Citado por Lukács, op. cit., p. 88.

34

Palma, "Muerta en vida», op. cit., pp. 94-97 (p. 94). su voluntad de crear una opinión pública que ayudase a los peruanos a autodeterminarse, a salir de su infancia, seguía chocando con una negativa tradición lectora. Para captar la atención de este frágil público lector, Palma adorna «con las galas del romance toda narración histórica», como escribía en "Un virrey y un arzobispo»; pero todavía hace más, elabora un estilo que lo aproxime a una tradición oral y popular que facilite el crecimiento de ese público. Palma va a referir sus historias "como el vulgo y las viejas cuentan cuentos", según la atinada observación de Valera. Se diría que lo escuchamos hablar. Logra así un nuevo ideal de lengua literaria que acerca el texto a la lengua de la conversación; aunque la aparente espontaneidad sea en realidad, el resultado de un intenso y calculado trabajo. El encanto que seduce al lector proviene, en buena medida, de la sensación de cercanía al autor; el resto, del humor y la ironía de su decir. Se trata de una ironía, por otra parte, que nunca tiene por objeto al lector. Por el contrario, éste se convierte en un compañero divertido y privilegiado ${ }^{29}$.

Con el desarrollo de este estilo, Palma consigue hacer de las Tradiciones la «minuciosa reducción de la historia a una charla familiar» ${ }^{30}$. Y de su propia voz, el personaje más constante de las series, junto a su complemento imprescindible: el lector. Un trazo aquí y otro allá permite a los lectores recomponer la imagen de este Palma personaje. "No en vano -apunta Cornejo-, corridos los años, el propio Palma será imaginado como el abuelo memorioso y cordial que cuenta a los peruanos historias de familia» ${ }^{31}$.

Con esta estrategia, que garantiza la presencia del presente republicano y orienta la visión del pasado, el lector se convierte en algo parecido a su confidente. Ninguna situación más adecuada, entonces, para convencer a este lector, oyente y amigo, de lo justo y verdadero de las ideas y valores que se le confían.

En realidad, este vaporoso personaje de Palma, más que un personaje, con sus complejidades y singularidades, es un tipo: ese escritor liberal comprometido con su siglo y su idea de progreso, al que se refirió en más de una ocasión:

Yo creo que el poeta y el artista han de ser, ante todo, hombres de la época en que les cupo en suerte vivir. Bello es soñar, imaginarse lo que fue; pero más bello es aún extasiarse en las conquistas del presente, para deducir de ellas las maravillas que lo porvenir encierra (Recuerdos de España) $)^{32}$.
Pese a su posible condición histórica, la caracterización de tipo cuadra todavía mejor a los protagonistas de sus Tradiciones: virreyes, arzobispos, magistrados, frailes, hijas o hermanas y galanes. La explicación la proporciona Balzac en el prólogo a una de sus novelas al comentar las diferencias entre sus obras y las de Walter Scott:

Walter Scott ha agotado la única novela posible acerca del pasado. Esa novela es la lucha del siervo o del burgués contra el noble, de la nobleza contra la iglesia, de la nobleza y la iglesia contra la monarquía.

Es decir, se trata de relaciones relativamente simples, porque son relaciones estamentales.

Hoy -continúa Balzac- la igualdad ha producido en Francia matices infinitos. En otro tiempo la casta daba a cada cual su fisonomía, lo cual ha dominado su individualidad; hoy cada individuo cobra por sí mismo su fisonomía ${ }^{33}$.

La misma explicación vale para las Tradiciones, tengan por contexto la colonia o la República, pues en este último caso lo que se denuncia es la pervivencia de las viejas estructuras estamentales. Palma se esfuerza por dar forma a las luchas y contraposiciones mediante personajes que representan las corrientes sociales y las fuerzas históricas. La colonia, ámbito prioritario de las Tradiciones, se revela así como una época de tensiones múltiples y dinámicas, similares a las enumeradas por Balzac, y alejada, por lo tanto, de esa imagen tranquila y bonancible a la que se refieren quienes se empeñan en hacer de Palma un colonialista. Se perciben así los enfrentamientos entre el estado y la iglesia - «Un virrey y un arzobispo»-, entre el estado y el frente de aristocracia y pueblo -«Pues bonita soy yo, la Castellanos»-, entre órdenes religiosas religiosas -«Un virrey hereje y un campanero bellaco»-, etcétera.

Pero Palma, que se ocupa de virreyes y de arzobispos, no se olvida tampoco de lo doméstico, porque es consciente de que la opresión todo lo permea; ni de que, para hacer sensibles los motivos sociales y humanos, a menudo son más adecuados los acontecimientos ínfimos y las situaciones menores que los grandes dramas políticos. Por ello leemos en «Muerta en vida»: « $¡ E l$ amor se cría! Frase inmoral que servía de sinapismo para debilitar los latidos del corazón de la mujer, frase típica que pinta por completo el despotismo en la familia» ${ }^{34}$. 